\title{
Soil Salinity Enhances Phytophthora Root Rot of Tomato but Hinders Asexual Reproduction by Phytophthora parasitic
}

\author{
T.J. Swiecki' and J.D. MacDonald ${ }^{2}$ \\ Department of Plant Pathology, University of California, Davis, CA 95616
}

\begin{abstract}
Additional index words. plastochron index, salt stress, predisposition, disease resistance, Lycopersicon esculentum
'Abstract. Exposure of tomato plants (Lycopersicon esculentum Mill.) to salinity stress either before or after inoculation with Phytophthora parasitica increased root and crown rot severity relative to nonstressed controls. The synergy between salinity and $P$. parasitic was most pronounced on young (prebloom) plants and least pronounced on older (postbloom) plants. Salt stressed, inoculated plants had significantly reduced top weight, significantly more root necrosis, greater incidence of crown necrosis, and significantly greater mortality. Increased disease severity occurred even though experiments showed salinity reduced zoospore release arid motility of $P$. parasitic, suggesting that even low inoculum levels can result in severe root rot on young tomato plants in saline soils.
\end{abstract}

Excess salinity affects soils in most arid and semi-arid regions where irrigated agriculture is practiced, including a large portion of the agricultural soils in California's interior valleys (Backlund and Hoppes, 1984). The processing tomato is an important crop in California, with large tracts planted annually in the Sacramento and San Joaquin valleys. Commercial tomato cultivars have been characterized as having low (Rush and Epstein, 1976) to moderate (Sacher et al., 1983) salt tolerance, and research aimed at developing cultivars with greater tolerance has been underway for some time (Rush and Epstein, 1976; Sacher et al., 1983).

Processing tomatoes in California are also frequently affected by Phytophthora root and crown rot, caused primarily by $P h y$ tophthora parasitic Dastur. (Bolkan, 1985; Ioannou and Grogan, 1984; Satour and Butler, 1967). This disease can cause severe losses (Richardson, 1941; Satour and Butler, 1967), especially if plants are subjected to prolonged irrigations (Ristaino et al., 1989). Efforts are being made to identify sources of resistance to Phytophthora root rot and incorporate them into commercial cultivars (Blaker and Hewitt, 1987; Bolkan, 1985). However, if breeders are to successfully detect and deploy stable resistance, environmental factors that influence host susceptibility must also be considered. This approach has recently been employed in efforts to detect $P$. cryptogea resistance in safflower (Heritage and Harrigan, 1984).

Salinity stress has been shown to increase the susceptibility of citrus and chrysanthemum to Phytophthora root rots (Blaker and MacDonald, 1986; MacDonald, 1982, 1984; Swiecki and MacDonald, 1988), and to increase the susceptibility of tomato to root knot nematode (Edongoli and Ferris, 1982; Maggenti and Hardan, 1973). In addition, high levels of fertilizer salts increased damping-off of tomato seedlings caused by Rhizoctonia solani or Fusarium oxysporum f.sp. Iycopersici (Beach, 1949). Bouchibi et al. (1990) showed that relatively low levels of salinity ( 25 to $50 \mathrm{meq}$ ) could increase the severity of Phytophthora root rot of tomato at high $\mathrm{Na}$ : Ca ratios $(10: 1)$. But those experiments were designed to study the more subtle effects

Received for publication 14 May 1990. This research was supported in part by USDA Grant 80-CRCR-1-0426. The cost of publishishing this paper was defraved in part by the payment of page charges. Under postal regulations, this paper therefore must be hereby marked advertisernent solely to indicate this fact.

${ }^{1}$ Former Graduate Student. Present address: Plant Science Consulting \& Research, 1027 Davis Street, Vacaville, CA 95688.

${ }^{2}$ Associate Professor. of ion interactions and did not involve the kinds of plant stress that can occur in saline soils and that have been the target of breeding efforts. In addition to affecting the host (MacDonald, 1982, 1984; Swiecki and MacDonald, 1988), soil salinity may affect the survival and behavior of the pathogen (Blaker and MacDonald, 1985; Bouchibi et al., 1990) in ways that have not been fully elucidated.

The purpose of this study was to determine the extent to which salinity stress influences the severity of Phytophthora root rot of tomato and the secondary inoculum cycle of $P$. parasitic. Several methods of applying and relieving salinity stress were employed in an attempt to mimic the dynamic fluctuations of salinity that occur in field soils (Rhoades, 1972).

\section{Materials and Methods}

Seeds of the processing tomato cultivars UC82-B (UC) and VF145-B-7879 (VF) were germinated in a greenhouse in flats of UC Mix (Matkin and Chandler, 1957). Three weeks after germination, seedlings were individually transplanted into 10cm-diameter (0.38 liter) plastic pots and maintained in a greenhouse or growth chamber for varying amounts of time to obtain plants of various maturities. Because chronological age was not a reliable indicator of developmental stage, we calculated the plastochron index (PI) of plants used in various experiments (Coleman and Greyson, 1976; Erickson and Michelini, 1957). A plant PI of $n$ indicates that the nth leaf had attained the reference length, which in these experiments was $10 \mathrm{~mm}$. Since PI is valid only until the time of flower bud initiation (Coleman and Greyson, 1976), a phonological scale was also devised and used in addition to PI. Phonological stage (PS) was based upon anthesis of the first set of flowers such that $\mathrm{O}=$ no flower buds visible; 1 = flower bud initials present but $\leq 5 \mathrm{~mm}$ long; $2=$ flower buds longer than $5 \mathrm{~mm}$ but unopened; $3=$ flowers fully open; and $4=$ flowers past bloom. A relative measure of plant age in each experiment was obtained by determining the PI and PS of control plants at harvest (PIh and PSh, respectively).

Zoospore suspensions of a pathogenic isolate of $\mathrm{P}$. parasitic [isolate "30-2 DM" (Bernhardt and Grogan, 1982)] were obtained by cutting 5-mm-diameter plugs from the margins of 6day-old V8 juice agar (Mircetich and Matheron, 1976) colonies, and placing them in petri plates containing autoclave $10 \%$ soil extract (MacDonald, 1982). The plates were incubated in light at 22 to $24 \mathrm{C}$ for $24 \mathrm{~h}$ to induce sporangium formation (Bernhardt and Grogan, 1982), after which zoospore release was stimulated 
by chilling the petri plates for $10 \mathrm{~min}$ at $4 \mathrm{C}$. One hour after chilling, zoospores were separated from the agar plugs by filtration through cheesecloth, and the concentration in suspension was determined with a hemocytometer. In some experiments, colonies grown on V8 juice/vermiculite (Mircetich and Matheron, 1976) were used to infest soil. The colonized vermiculite was rinsed with water to remove residual nutrients, ground to a slurry in an electric blender $(0.5 \mathrm{ml}$ distilled water $/ \mathrm{ml}$ vermiculite), and portions thoroughly mixed with known volumes of soil. In other experiments, 8-mm-diameter disks of aerial mycelium, taken from 14-day-old cultures grown on pea-dextrose agar (MacDonald and Duniway, 1978), were placed on the soil surface in pots containing tomato plants, and covered with 4 to $8 \mathrm{~mm}$ of pasteurized soil.

In all experiments, salinity and inoculation treatments were combined in a $2 \times 2$ factorial design yielding four plant treatments: control, inoculated only, salt-stressed only, and saltstressed, inoculated. A minimum of five plants per treatment was used in each experiment and all experiments were repeated at least three times.

Preinoculation salt stress. Relatively young (chronological age at harvest $=5$ to 7 weeks; $\mathrm{PIh}=8$ to 10 and $\mathrm{PSh}=0$ ) UC and VF plants were used in all experiments involving preinoculation stress. For solution culture experiments, seedlings were transferred to 1.8-liter crocks containing $0.5 \times$ Hoagland's solution \#1 (Hoagland and Arnon, 1950), with one UC and one VF plant in each crock. The plants were maintained in a growth chamber at 23C day/18C night and a 14-h photoperiod. Photosynthetically active radiation was measured at the plant canopy with a LI-COR model LI-190SB quantum sensor (LI-COR, Lincoln, Neb.) and averaged $560 \mu \mathrm{mol} \cdot \mathrm{s}^{-1} \cdot \mathrm{m}^{-2}$. Plants were exposed to salinity by adding $\mathrm{NaCl}+\mathrm{CaC1}_{2}$ in a $5: 1$ equivalent ratio to the nutrient solution, such that the salt concentration was increased in 25-meq steps over 6 days to a final concentration of $150 \mathrm{meq} \cdot \mathrm{liter}$ and an electrical conductivity (EC) of $16.5 \mathrm{dS} \cdot \mathrm{m}^{-1}$. All plants then were transferred to fresh, nonsaline nutrient solution and half were inoculated by adding $5.2 \mathrm{x}$ $10^{6}$ zoospores of $P$. parasitica per crock $\left(3 \times 10^{6}\right.$ zoospores/ liter solution). Plants were inspected daily thereafter for evidence of disease. Six days after inoculation, the experiment was terminated. The percentage of rotted roots was estimated visually using a scale of $\mathrm{O}$ to 5 , wherein $\mathrm{O}=$ no discoloration, $1=$ less than $10 \%, 2=10 \%$ to $<33 \%, 3=33 \%$ to $<66 \%$, $4=66 \%$ to $90 \%$, and $5=$ more than $90 \%$ discoloration. Plants were removed from the crocks, cut at the crown to separate shoots and roots, dried for $48 \mathrm{~h}$ at $90 \mathrm{C}$, and weighed.

In experiments with plants grown in soilless medium, one UC and one VF plant were transplanted into each of thirty-two 0.38 -liter pots containing UC mix. Plants were grown in a greenhouse and irrigated daily with $0.1 \times$ Hoagland's solution. After 12 days, half the plants were salinized by daily irrigation with $0.1 \times$ Hoagland's amended with $\mathrm{NaCl}+\mathrm{CaC1}_{2}(5: 1$ equivalent ratio). The salt concentration in the irrigation solution was increased in three equal steps, at 4-day intervals, to a maximum EC of $16 \mathrm{dS} \cdot \mathrm{m}^{-1}$. The EC of the saturated soil extract (ECe) in the potting medium was determined periodically, and ranged from 0.5 to $1.5 \mathrm{dS} \cdot \mathrm{m}^{-1}$ higher than the corresponding irrigation solutions. Twelve days after initiating the salt treatments, the soil in all pots was leached with $0.1 \times$ Hoagland's until the effluent from the bottom of saline treatment pots had an EC $<1 \mathrm{dS} \cdot \mathrm{m}^{-1}$. After leaching, half the plants in the saline and nonsaline treatments were inoculated with $1.5 \times 10^{6}$ zoospores of $P$. parasitic per plant $\left(8 \times 10^{6} /\right.$ liter soil $)$ and the soil in the pots was kept saturated for $24 \mathrm{~h}$. All plants then were irrigated daily for 7 days with $0.1 \times$ Hoagland's, after which they were harvested, examined for crown cankers, and shoot and root dry weights determined.

These experiments were repeated, with slight modification, to examine the influence of plant age on disease development. UC seedlings were transplanted into 10-, 13-, or 15-cm-diameter pots $(0.38,0.8$, and 1 liter, respectively) containing a sandyolo loam (YL) mixture $(2: 1)$, and were maintained in a greenhouse or growth chamber (32C day/18C night) for 7 to 60 days before salt treatments were started. Salts were added with irrigation solutions as described above, using a 1:1 equivalent ratio of $\mathrm{NaCl}$ and $\mathrm{CaCl}_{2}$ and increasing the solution $\mathrm{EC}$ in four equal steps over 8 days to a maximum of $7 \mathrm{dS} \cdot \mathrm{m}^{-1}$. Plants were inoculated by placing four to 10 mycelial disks (10 disks/liter soil) in each pot on the 8th day. One day later, the soil in all pots was leached with $0.1 \times$ Hoagland's, which was used for all subsequent irrigations, and 2 weeks later the plants were harvested and evaluated for symptom severity.

Postinoculation salt stress. To determine the effects of salt stress on existing root infections, UC seedlings were transplanted into pasteurized YL soil that had been infested with $P$. parasitica by addition of colonized vermiculite $(0.2 \% \mathrm{v} / \mathrm{v})$. Control plants were transplanted into noninfested soil and all plants were subsequently maintained in growth chambers as described above, except with days at 32C. Salts were introduced via irrigation as described above, except that the EC of the irrigation solution was increased to a maximum of $16 \mathrm{dS} \cdot \mathrm{m}^{-1}$ in four equal steps over 8 days, and the $24 \mathrm{~h}$ of saturation after leaching was omitted.

In the first experiment, 20-day-old UC seedlings were transplanted into 100-ml pockets of noninfested YL in the center of 1-liter pots filled with infested soil. Salt treatments were started 10 days after transplanting and the experiment was terminated 11 days later. In a second experiment, 21-day-old UC seedlings were transplanted into 0.38 -liter pots of YL, maintained in a greenhouse for an additional 21 days, and then transplanted into 1-liter pots containing infested soil. Salt treatments were started 3 days later and the experiment was terminated after an additional 15 days. In both experiments, time of plant death was recorded if before harvest. At harvest, plant crowns were examined for evidence of cankers, and the severity of foliar and root symptoms was determined. Above-ground symptoms were rated on a scale of $\mathrm{O}$ to 3 , where $\mathrm{O}=$ no symptoms and $3=$ plants severely wilted/desiccated. Root systems were washed free of soil and root rot severity also was estimated on a scale of 0 to 3 , where $0=$ no visible $\operatorname{rot}$ and $3=$ more than $80 \%$ of the root system rotted.

Salinity effects on P. parasitic in vitro. Unless otherwise stated, all experiments were done at ambient laboratory temperatures (24 to $27 \mathrm{C}$ ). Agar disks (5-mm diam) were cut from the margins of 6-day-oId V-8 juice agar cultures of $P$. parasitic and placed into 6-cm-diameter petri plates (three disks per plate). Solutions of $\mathrm{NaCl}$ and $\mathrm{CaCl}_{2}$ (1:1 equivalent ratio) in distilled water or sterile $10 \%$ soil extract were added to the plates $(8 \mathrm{ml} /$ plate, solution depth $=4 \mathrm{~mm}$ ). The disks were incubated for $24 \mathrm{~h}$ to allow sporangium formation, and then chilled at $4 \mathrm{C}$ for $10 \mathrm{~min}$ to stimulate zoospore release. Disks were removed $1 \mathrm{~h}$ after chilling, fixed with acid fuchsin in lactic acid, and mounted on glass slides. Each disks was examined at 100× magnification and the number of full, empty, and irregular (sporangium contents abnormal in appearance) sporangia in three fields of view was counted. 
Zoospore release was quantified by spotting 10 - to $30-\mu \mathrm{l}$ aliquots of the incubation solutions onto plates of cornmeal agar. After 4,10 , or $24 \mathrm{~h}$ of incubation at $25 \mathrm{C}$, plates were irradiated with ultraviolet light to kill cysts and germlings and stained with acid fuchsin or methylene blue. The number of germinated and nongerminated zoospore cysts in each spot at each time was counted under a microscope at 100× magnification. Additionally, the length of zoospore motility in the incubation solutions was determined by examining each solution at intervals of 0.5 to $1 \mathrm{~h}$ after the disks were removed and estimating the proportion of motile to encysted zoospores. Examinations were terminated-when $95 \%$ of the zoospores had encysted.

Salinity effects on P. parasitic in vivo. Experiments also were conducted to evaluate sporangium formation and zoospore release in soil in the presence of tomato roots. UC seedlings were transplanted into 1-liter pots containing a 2 sand : 1 YL soil mixture $(\mathrm{v} / \mathrm{v})$, which drained more uniformly than YL alone. Plants were maintained in a greenhouse for $\approx 60$ days before salt treatments were started. At their initiation, the plants were divided into three groups. One group continued to receive the irrigation solution with no added salt $\left(E C=0.2 \mathrm{dS} \cdot \mathrm{m}^{-1}\right)$, while plants in the other two groups received irrigation solution amended with $\mathrm{NaCl}$ and $\mathrm{CaCl}_{2}$ (in a 1:1 equivalent ratio). The solution $\mathrm{EC}$ in these treatments was increased in four equal steps over 8 days to a maximum of $7 \mathrm{dS} \cdot \mathrm{m}^{-1}$. One day after the maximum salt levels had been reached (day 9), one group of salinized plants was leached and subsequently irrigated with nonsaline irrigation solution as described above. Plants in the remaining salinized group continued to receive the $7 \mathrm{dS} \cdot \mathrm{m}^{-1}$ irrigation solution for the duration of the experiment. This provided three salt treatments; no salt (NS), leached salt (LS), and continuous salt (CS).

On day 8,12 mycelial disks were buried 2 to $3 \mathrm{~cm}$ below the soil surface in every pot. The disks were enclosed individually in 15-mm-square plastic mesh envelopes having $0.5-\mathrm{mm}$ openings. Two disks were recovered from each pot on day 9 , just before the leaching treatment, and at daily intervals over the next 5 days. Harvested disks were fixed in buffered $2.5 \%$ glutaraldehyde $(\mathrm{pH} 7.2)$ and stored at $4 \mathrm{C}$, after which they were ground in distilled water in a microblender, stained with $1 \%$ safranin in $95 \%$ ethanol, and the number of full or empty sporangia was counted at $100 \times$ using a hemocytometer.

In addition to determining sporangium formation on the buried disks, zoospore activity in the pots was assessed two times. On day 9, when soils in the LS treatment were leached, pots in the NS and CS treatments were also flushed with similar volumes of their respective irrigation solutions. Saucers were placed beneath each pot to trap drainage solutions and 2-week-old tomato seedlings (CV. Early Pac 7) were unpotted, washed, and floated in the solutions as bait plants. Baits remained in the drainage solutions for 4 to $6 \mathrm{~h}$, after which they were placed on damp paper towels in moist chambers placed inside a growth chamber (29C day/25C night, 14-h photoperiod). Large watersoaked lesions usually developed within 3 days on the hypocotyls of infected baits, and the presence of $P$. parasitic was confirmed by culturing tissue pieces on cornmeal agar. This baiting procedure was repeated 12 days later (day 21) to detect possible secondary inoculum cycles, after which all plants were harvested and evaluated for root rot symptoms.

\section{Results}

Preinoculation salt stress. In solution culture experiments, $P$. parasitic caused relatively low levels (10\% to $15 \%)$ of root rot on nonstressed plants, but caused extensive necrosis $(60 \%$ to $70 \%$ ) on roots of plants exposed to salt stress (Fig. 1A). Indeed, many $(69 \%)$ of the salt-stressed plants developed large, brown lesions on their lower stems; a symptom never observed on nonstressed plants. There was some root discoloration associated with the salt treatments themselves (Fig. 1A), but much less than the salt plus inoculation. Root symptoms were significantly affected by inoculation $(P<0.001)$, salt exposure $(P$ $<0.001)$, and the interaction of these factors $(P<0.005)$. While visual symptoms clearly showed a synergistic effect between salinity and $P$. parasitic, this interaction was not clearly reflected in root dry weights (Fig. 1B). Dry weight of roots was significantly reduced by inoculation $(P<0.05)$ and salt exposure $(P<0.001)$, but the interaction term was not significant $(P>0.5)$.

Similar results were obtained in experiments where plants were grown in pots of UC mix and inoculated with $P$. parasitic zoospores after the soil had been salinized and leached to relieve salt stress. Plants were harvested 8 days after inoculation, at which time all salt-stressed, inoculated plants were wilted, and
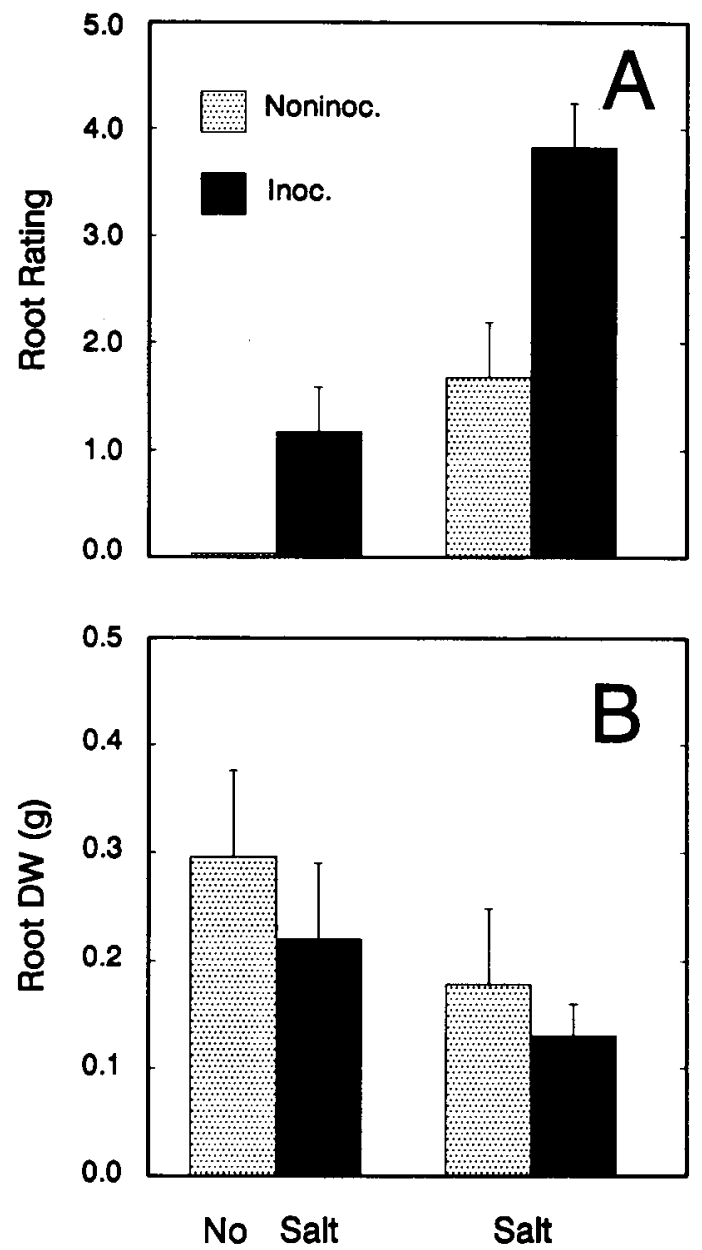

Fig. 1. Effects of Phytophthora parasitic and preinoculation salt stress on (A) root rot symptoms and (B) root dry weight of young (5- to 7-week-old; PIh $=8$ to $10, \mathrm{PSh}=0$ ) tomato plants grown in solution culture. Data for tomato cultivars UC82-B and VF145B-7879 were pooled for analysis. Vertical lines represent \pm 1 SD. Salt and inoculation treatments caused significant increases in root necrosis $(P<0.001)$ and significant decreases in root dry weight . $(P<0.05)$. The interaction between salt and inoculation was significant for root symptoms $(P<0.05)$, but nonsignificant for root dry weight. 

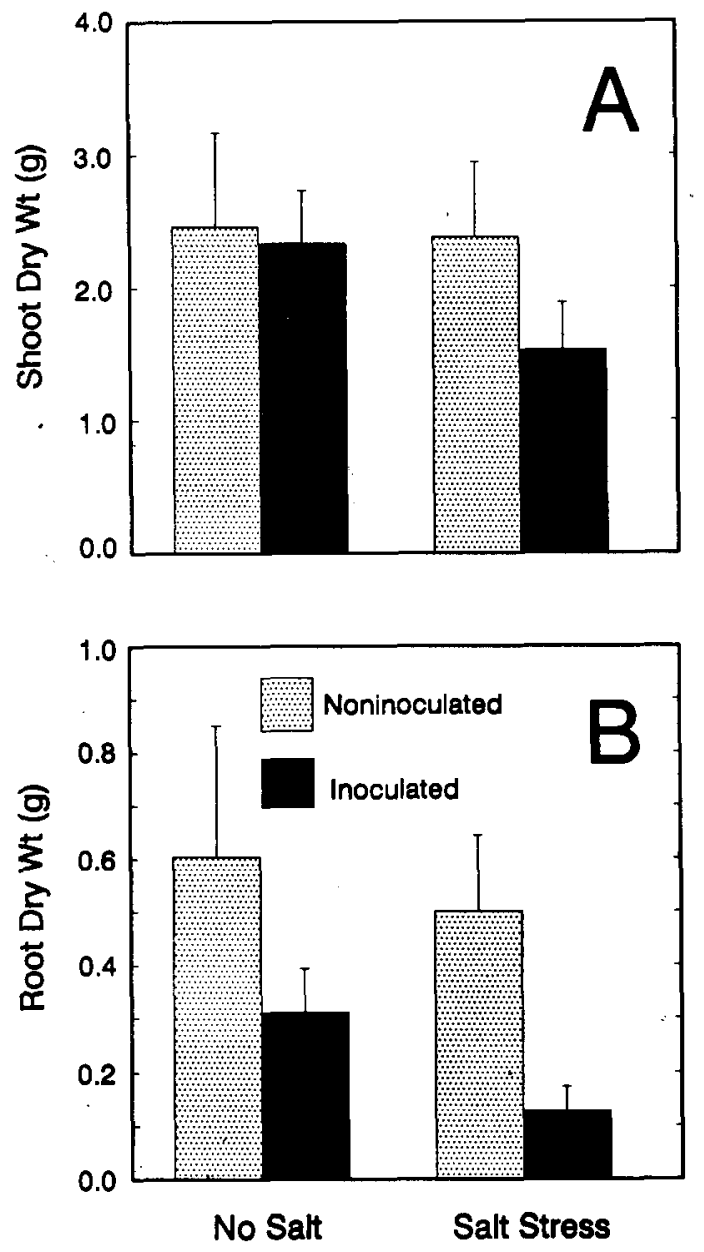

Fig. 2. Effects of Pkytophthora parasitica and preinoculation salt stress on (A) shoot dry weight and (B) root dry weight of young (7week-old; PIh $=8$ to 10 , PSh $=0$ ) tomato plants grown in UC mix. Data for tomato cultivars UC82-B and VF145-B-7879 were pooled for analysis. Vertical lines represent \pm 1 SD. Salt and inoculation treatments alone had no significant effect on shoot dry weight $(P>0.5)$, but did cause significant reductions in root dry weight $(P<0.05$ for salt, $P<0.001$ for inoculation). The interaction between salt plus inoculation was significant for shoot dry weight $(P<0.01)$ and nonsignificant for root dry weight.

most (11/16) had developed crown lesions. No wilt or crown lesions developed on plants exposed only to salt stress or $P$. parasitic. Shoot weight was not significantly reduced by the individual effects of inoculation or salt exposure, but was significantly reduced by the combined interaction of these factors $(P=0.007)$ (Fig. 2A). By contrast, salt and inoculation had highly significant effects enroot dry weight $(P<0.001)$, but the interaction term was not significant $(P=0.27)$ (Fig. 2B).

In experiments with plants of different age, we found disease symptoms, particularly the development of crown necrosis, to be most severe in younger plants $(\mathrm{PIh}=8.9$, PSh $=0.9$ ) that had been exposed to salt stress before inoculation (Table 1). Little to no crown necrosis developed on older plants (PIh 10.6 and 16.2), and the salt-related increase in root symptom severity was less pronounced (NS and $P=0.04$ for $\mathrm{PIh}=10.6$ and 16.2, respectively) (Table 1 ).

Postinoculation salt stress. When 20-day-old (PI = 3, PS = $0)$ UC seedlings were transplanted into $P$. parasitica-infested YL soil, $\approx 30 \%$ developed crown cankers and died during the 10-day establishment period. Surviving plants were assigned at
Table 1. Effects of salt stress on symptom severity in tomato (cv. UC82-B) plants of different ages inoculated with Pfiytophthora parasitica.

\begin{tabular}{|c|c|c|c|c|}
\hline \multicolumn{2}{|c|}{ Plant age } & \multirow{2}{*}{$\begin{array}{c}\text { Salt } \\
\text { stress }^{y}\end{array}$} & \multirow{2}{*}{$\begin{array}{c}\text { Plants with } \\
\text { crown necrosis } \\
(\%)\end{array}$} & \multirow{2}{*}{$\begin{array}{c}\text { Mean } \\
\text { root rot } \\
\text { ratingx }\end{array}$} \\
\hline PIh & PSh & & & \\
\hline \multirow[t]{2}{*}{8.9} & 0.9 & - & 0 & $0.4(0.16)$ \\
\hline & & + & 40 & $1.6(0.40)$ \\
\hline \multirow[t]{2}{*}{10.6} & 1.6 & - & 0 & $1.5(0.27)$ \\
\hline & & + & 10 & $1.9(0.18)$ \\
\hline \multirow[t]{2}{*}{16.2} & 1.4 & - & 0 & $1.0(0.00)$ \\
\hline & & + & 0 & $1.6(0.24)$ \\
\hline
\end{tabular}

${ }^{2} \overline{P l}$ lant age expressed as plastochron index and phonological stage at harvest (PIh and PSh, respectively).

${ }^{y}$ Maximum electrical conductivity of irrigation solution $=7 \mathrm{dS} \cdot \mathrm{m}^{-1}$. ${ }^{x}$ Root rot symptoms evaluated on a scale of 0 to 3 , where $0=$ no visible symptoms and $3=$ all roots rotted. (Standard error of the mean. )

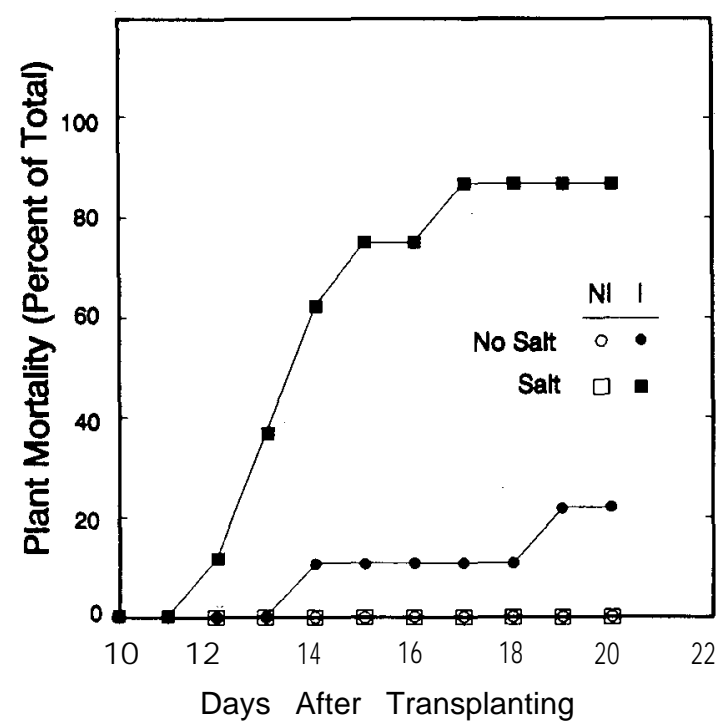

Fig. 3. Effect of salt stress on the survival of young (7-week-old; $\mathrm{PIh}=8, \mathrm{PSh}=0$ ) tomato plants $(\mathrm{cv} . \mathrm{UC} 82-\mathrm{B})$ growing in $P$. parasitica-infested (I) and pathogen-free (NI) Yolo loam. Plant mortality was significantly affected by salt, inoculation, and the interaction of these factors $(P<0.001)$.

random to the saline or nonsaline irrigation treatments and above-ground disease symptoms were followed over the next 11 days $(\mathrm{PIh}=8$, PSh $=0)$. The extent of subsequent plant mortality was significantly influenced by salinity treatment. Only $20 \%$ of the plants grown in infested soil that were not exposed to salinity died (Fig. 3). This was in contrast to nearly $85 \%$ mortality among the plants grown in infested soil and exposed to progressively increased salinity stress (Fig. 3). At harvest, the remaining nonstressed plants had no discernible above-ground symptoms and only moderate root rot symptoms (average root rating $=2.2$ ). Surviving plants exposed to salinity stress were severely wilted and nearly all of their roots rotted.

Salinity effects on $\mathrm{P}$. parasitic in vitro. Relative to the nonsaline controls, sporangium formation was greater in salt solutions having EC values between 1.2 to $11.8 \mathrm{dS} \cdot \mathrm{m}^{-1}$ (Fig. 4). Sporangium formation was reduced, relative to the nonsaline controls, only at EC values $>18 \mathrm{dS} \cdot \mathrm{m}^{-1}$ (data not shown). But, although sporangia formed abundantly at EC values between $\mathrm{O}$ and $12 \mathrm{dS} \cdot \mathrm{m}^{-1}$, the number that released zoospores after chill- 


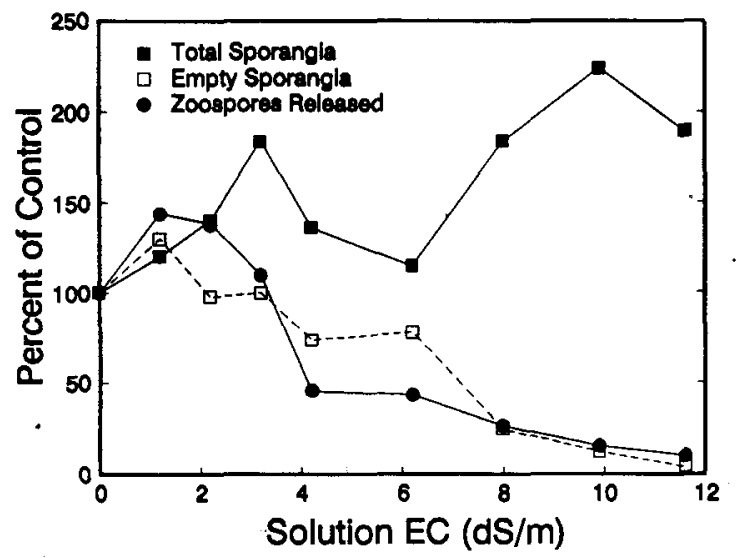

Fig. 4. Influences of salt concentration on sporangium formation and zoospore release by Phytophthora parasitica in vitro. Data are expressed as percent of mean values in the distilled water $(\mathrm{EC}=0)$ control.

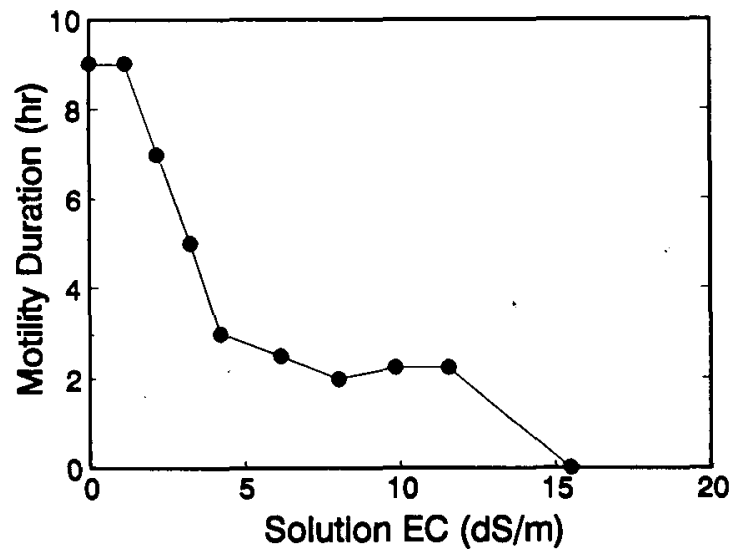

Fig. 5. Influence of salt concentration on the duration of zoospore motility by Phytophthora parasitica in vitro. Duration is expressed as number of hours required for $>95 \%$ of the zoospores to encyst.

ing decreased markedly at EC values of 4 to $6 \mathrm{dS} \cdot \mathrm{m}^{-1}$ and was only $25 \%$ of the controls at $8 \mathrm{dS} \cdot \mathrm{m}^{-1}$ (Fig. 4). In addition, the duration of zoospore motility decreased sharply as EC increased from 1.5 to $4 \mathrm{dS} \cdot \mathrm{m}^{-1}$ (Fig. 5). However, zoospore cysts obtained from solutions with EC values up to $6.3 \mathrm{dS} \cdot \mathrm{m} 1$ germinated readily when planted on cornmeal agar; > $90 \%$ germinated within $4 \mathrm{~h}$ and nearly all had germinated at $24 \mathrm{~h}$. At EC values $>8 \mathrm{dS} \cdot \mathrm{m}^{-1}$ cyst germination was reduced, with only $66 \%$ to $90 \%$ germinating after $24 \mathrm{~h}$ (data not shown).

In these experiments, we observed that up to $20 \%$ of the sporangia formed in salt solutions with EC values $>8 \mathrm{dS} \cdot \mathrm{m}^{-1}$ appeared abnormal, containing either dense, aggregated cytoplasm or encysted zoospores. Also, the sporangia that formed at EC levels $>12 \mathrm{dS} \cdot \mathrm{m}^{-1}$ were smaller and stained less intensely with acid fuchsin than those formed at lower EC values.

Salinity effects on $\mathrm{P}$. parasitica in vivo. When mycelial disks were recovered at daily intervals from pots of soil in the NS, LS, and CS treatments, many sporangia were detected in all treatments. However, relative to the NS and LS treatments, more irregular-appearing sporangia and fewer empty sporangia were found in the CS treatment (data not shown). Further, when tomato seedling baits were used to detect the presence of $P$. parasitica zoospores in solutions draining from the pots on day 9, and again 12 days later, the proportion of infected baits was high $(77 \%$ to $97 \%)$ in the NS and LS treatments, and was significantly lower in the CS salt treatment (Table 2).

\section{Discussion}

We found that salinity stress increased Phytophthora root and crown rot severity in both tomato cultivars used in these experiments, and that the interaction between salinity and $P$. parasitica was most significant in young (prebloom) plants. Young plants (PIh $=8$ to 10 ) exposed to salinity and $P$. parasitic had significantly more root necrosis (Fig. 1A), significantly reduced top weight (Fig. 2A), a higher incidence of crown infection (Table 1), and a significantly higher incidence of plant mortality (Fig. 3) than corresponding nonstressed plants. Older plants (PIh $=10.6$ to 16.2 ) exposed to salinity before inoculation had a low incidence of crown infection and developed only slightly more severe root rot symptoms than nonstressed plants (Table 1). While disease was clearly" "most severe in saltstressed, inoculated plants, the root dry weight measurements indicated an additive rather than synergistic effect of the salt and inoculation treatments (Figs. 1B, 2B). The failure of root dry weights to reflect the interaction observed with other measures of disease (Figs. 1A, 2A, 3) may have been due to the relatively short time (i.e., 6 to 8 days) between inoculation and harvest.

In all these experiments, we exposed plants to progressively increased salt levels, followed by leaching, because we felt this treatment more closely simulated field conditions. In irrigated crops, salt concentrations in the soil solution fluctuate widely over time, becoming progressively higher as water is lost through evapotranspiration and abruptly lowering with the application of irrigation water (Rhoades, 1972). Using this approach, symptom severity on young plants increased irrespective of whether they were exposed to salinity before or after inoculation; but appeared to be directly related to the degree of stress. For example, there was a $40 \%$ incidence of crown necrosis among plants exposed to moderate salinity $\left(\mathrm{EC}=7 \mathrm{dS} \cdot \mathrm{m}^{-1}\right.$, Table $1)$, while plants exposed to high salinity $\left(\mathrm{EC}=16 \mathrm{dS} \cdot \mathrm{m}^{-1}\right)$ before or after inoculation had $69 \%$ and $83 \%$ incidence of crown cankers, respectively, resulting in a high incidence of plant mortality (Fig. 3). A similar positive relationship between root disease severity and plant stress resulting from high levels of sodium/ calcium salts (Blaker and MacDonald, 1984; MacDonald, 1982,

Table 2. Effect of salinity on the colonization of tomato seedling baits used to detect Phytophthora parasitica in irrigation solution leachates from pots containing inoculated tomato plants (CV. UC82-B),

\begin{tabular}{lcc}
\hline & \multicolumn{3}{c}{$\begin{array}{c}\text { Percent baits infected } \\
\text { (days after inoculation) }\end{array}$} \\
\cline { 2 - 3 } Salt ${ }^{\mathrm{z}}$ & 1 & 12 \\
\hline None & 77 & 97 \\
Leached & 89 & 82 \\
Constant & $6^{\mathrm{x}}$ & $9^{\mathrm{x}}$ \\
\hline
\end{tabular}

${ }^{7}$ No salt $=$ plänts irrigated with $0.1 \times$ Hōagland's solution only. Leached salt $=$ plants irrigated 8 days with step-increased salt solutions (maximum $\mathrm{EC}=7 \mathrm{dS} \cdot \mathrm{m}^{-1}$ ), followed by leaching and subsequent irrigation with $0.1 \times$ Hoagland's solution. Constant salt $=$ plants irrigated 8 days with step-increased salt solutions (maximum EC $=7 \mathrm{dS} \cdot \mathrm{m}^{-1}$ ), followed by continued irrigation with $7 \mathrm{dS} \cdot \mathrm{m}^{-1}$ solution. Inoculum was added to soil on day 8, after maximum EC levels were reached. ${ }^{y}$ Results from two experiments were pooled and percentages are based on 34 plants per treatment. Bait plants were tomato cV. Early Pac 7. 'Differs significantly from the no salt treatment at $P<0.001$ according to Fisher's exact test on $2 \times 2$ contingency table. 
1984; Swiecki and MacDonald, 1988) or fertilizer salts (Beach, 1949; Dirks et al., 1980; Moorman, 1986) has been observed on other plants.

It is not clear how salinity stress has such a pronounced effect on disease severity in young plants, while having relatively little effect on older plants. In the case of chrysanthemum, there is evidence that salt stress interferes with host defense reactions, making the tissues more susceptible to pathogenic attack (MacDonald, 1984; Swiecki and MacDonald, 1988). However, in the case of citrus and tomato, the ability of plants to regenerate roots destroyed by Phytophthora has been noted as an important factor conferring field resistance (Blaker and MacDonald, 1985; Bolkan, 1985) .Indeed, in the postinoculation salt stress experiments (Fig. 3), the inoculated, nonstressed plants had moderate amounts of root rot, but also formed numerous, healthy adventitious roots at the crown. Salinity stress reduces plant growth rates (Bernstein, 1975; Dumbroff and Cooper, 1974) and, relative to older plants, young tomatoes are reported to be more sensitive to salinity and slower to recover from its effects (Dumbroff and Cooper, 1974; Lunin et al., 1963). Thus, even though exposed to similar levels of salt stress, older plants may be better able to compensate for the effects of disease.

While root growth and physiology of young tomato plants may have been inhibited by the levels of salinity used in these experiments, sporangium formation by $\mathrm{P}$. parasitica was not (Fig. 3). In fact, sporangium formation appeared stimulated by salinity, as the numbers of sporangia were generally higher $(120 \%$ to $225 \%$ ) in the salt-amended treatments than the distilled water controls (Fig. 4), an effect observed with other Phytophthora spp. as well (Blaker and MacDonald, 1985; Duniway, 1979). However, zoospore release (Fig. 4), motility (Fig. 5), and germination were reduced with increasing EC. While these data are based on in vitro experiments, they may explain the low levels of seedling bait infections in pots of soil exposed to the continuous salt treatments (Table 2).

Even though these data suggest that moderate to high salinity may reduce zoospore activity by $P$. parasitica, the postinoculation stress experiment (Fig. 3) showed that severe disease developed on plants, even" when the fungus was exposed to continuously high salt levels. This result indicates either that the disease progressed by means of vegetative growth of the pathogen, or that the effects of stress on the host are such that even low levels of secondary zoospore inoculum can result in severe root and crown rot. It also could mean that zoospore activity in soil is not reduced to the extent indicated by the laboratory experiments (Figs. 4, 5). In field soils, the salt concentration of the soil solution fluctuates with soil water content. When we placed mycelial disks in soil and exposed them to salinity levels of $7 \mathrm{dS} \cdot \mathrm{m}^{-1}$, followed by leaching with nonsaline solution, we found that the infection of seedling baits did not differ significantly from the nonsaline controls (Table 2). This result contrasted sharply with the low levels of bait infection in the continuous salt treatments (Table 2). Similarly, Blaker and MacDonald (1985) observed that sporangia of several Phytophthora isolates readily released zoospores if they formed in saline. soil and then were flooded with less-saline solutions.

The experiments reported here dealt with a single isolate of P. parasitic that originated from a nonsaline soil; it may or may not be representative of other isolates. Blaker and MacDonald (1985), in work with P. cryptogeu and citrus isolates of $P$. parasitic, reported possible ecological adaptations within species, with some isolates able to tolerate much higher levels of salinity than others. For example, an isolate of P. parasitic originating from nonsaline soils formed sporangia in soils with $\mathrm{EC}>10 \mathrm{dS} \cdot \mathrm{m}^{-1}$, but failed to release zoospores when flooded with solutions of low EC. On the other hand, an isolate originating from highly saline soils formed sporangia in soil at EC $=43 \mathrm{dS} \cdot \mathrm{m}^{-1}$ and released zoospores when flooded (Blaker and MacDonald, 1985). Similarly, Bouchibi et al. (1990) found that a tomato isolate of $P$. parasitica recovered from saline soil was more tolerant of salinity than one recovered from nonsaline soil. Thus, it is clear that salinity can affect zoospore activity in at least some Phytophthora spp. and that both the minimum and maximum levels of salinity during the irrigation cycle must be considered in assessing the impact of salinity on pathogen activity.

These results show that salinity stress can increase Phytophthora root and crown rot severity in tomatoes during early stages of growth. While these results are based on greenhouse and growth chamber experiments, we believe they have application to field-grown plants. Supportive evidence was obtained in a small field experiment where exposure of established, older plants to salinity and P. parasitica had little effect on root rot severity; but when seedlings were transplanted into the plots, there were large differences in plant mortality attributable to salt-Phytophthora interactions (Swiecki, 1984). Others, concerned with detecting resistance to Phytophthora root rot, have also found a strong correlation between greenhouse and field results (Blaker and Hewitt, 1987; Bolkan, 1985). Since field resistance in tomato may depend on root regeneration ability (Bolkan, 1985), and young plants are particularly sensitive to the effects of salt stress (Sacher et al., 1983), the performance of Phytophthora-resistant cultivars could be adversely affected in saline soils.

\section{Literature Cited}

Backlund, V.L. and R.R. Hoppes. 1984. Status of soil salinity in California. Calif. Agr. 38(10):8-9.

Beach, W.S. 1949. The effects of excess solutes, temperature and moisture upon damping-off. Pa. Agr. Expt. Sta. Bul. 509: 29 p.

Bernhardt, E.A. and R.G. Grogan. 1982. Effect of soil matric potential on the formation and indirect germination of sporangia of Phytophthora parasitica, P. capsici and P. cryptogea. Phytopathology 72:507-511.

Bernstein, L. 1975. Effects of salinity and sodicity on plant growth. Annu. Rev. Phytopathol. 13:295-312.

Blaker, N.S. and J.D. Hewitt. 1987. Comparison of seedling and mature plant resistance to Phytophthora parastica in tomato. HortScience 22:103-105.

Blaker, N.S. and J.D. MacDonald. 1985. The effect of soil salinity on formation of sporangia and zoospores by three isolates of Phytophthora. Phytopathology 75:270-274,

Blaker, N.S. and J.D. MacDonald. 1986. The role of salinity in the development of Phytophthora root rot of citrus. Phytopathology 76:970-975.

Bolkan, H.A. 1985. A technique to evaluate tomatoes for resistance to Phytophthora root rot in the greenhouse. Plant Dis. 69:708-709.

Bouchibi, N., A.H.C. van Bruggen, and J.D. MacDonald. 1990. Effect of ion concentration and sodium: calcium ratio of a nutrient solution on Phytophthora root rot of tomato and zoospore motility and viability of Phytophthora parasitic. Phytopathology 80:13231329.

Coleman, W.K. and R.I. Greyson. 1976. The growth and development of the leaf in tomato (Lycopersicon esculentum). I. the plastochron index, a suitable basis for description. Can. J. Bet. 54:2421-2428.

Dirks, V. A., T.R. Anderson, and E.F. Bolton. 1980. Effect of fertilizer and drain location on incidence of phytophthora rot in soybeans. Can. J. Plant Pathol. 2:179-183.

Dumbroff, E.B. and A.W. Cooper. 1974. Effects of salt stress applied 
in balanced nutrient solutions at several stages during growth of tomato. Bet. Gaz. 135:219-224.

Duniway, J.M. 1979. Water relations of water molds. Annu. Rev. Phytopathol. 17:431-460.

Endongali, E.A. and H. Ferris. 1982. Varietal response of tomato to the interaction of salinity and Meloidogyne incognita infection. J. Nematol. 14:57-62.

Erickson, R.O. and F.J. Michelini. 1957. The plastochron index. Amer. J. Bet. 44:297-304.

Heritage, A.D. and E.K.S. Harrigan. 1984. Environmental factors influencing safflower screening for resistance to P. cryptogea. Plant Dis. 69:767-769.

Hoagland, D.R. and D.I. Arnon. 1950. The water culture method for growing plants without soil. Ca.lif. Agr. Expt. Sta. Circ. 347.

Ioannou, N. and R.G. Grogan. 1984. Control of Phytophthora root rot of processing tomato with ethazole and metalaxyl. Plant Dis. 68:429435.

Lunin, J., M .H. Gallatin, and A.R. Batchelder. 1963. Saline irrigation of several vegetable crops at various growth stages. I. Effects on yields. Agron. J. 55:107-110.

MacDonald, J.D. 1982. Effect of salinity stress on the development of Phytophthora root rot of chrysanthemum. Phytopathology 72:214219.

MacDonald, J.D. 1984. Salinity effects on the susceptibility of chrysanthemum roots to Phytophthora cryptogea. Phytopathology 74:621624.

MacDonald, J.D. and J.M. Duniway. 1978. Influence of the matric and osmotic components of water potential on zoospore discharge in Phytophthora. Phytopathology 68:751-757.

Maggenti, A.R. and A. Hardan. 1973. The effects of soil salinity and Meloidogyne javanica on tomato. J. Nemato1. 5:231-234.
Matkin, O.A. and P.A. Chandler. 1957. The UC type soil mixes, p. 68-85. In: K.F. Baker (cd.). The UC system for producing healthy container-grown plants. Calif. Agr. Expt. Sta. Manual 23.

Mircetich, S.M. and M.E. Matheron. 1976. Phytophthora root and crown rot of cherry trees. Phytopathology 66:549-558.

Moorman, G.W. 1986. Increased plant mortality caused Pythium root rot of Poinsettia associated with high fertilizer rates. Plant Dis. 70:160162.

Rhoades, J.D. 1972. Quality of water for irrigation. Soil Sci. 113:277284.

Richardson, L.T. 1941. A Phytophthora tomato disease new to Ontario. Can J. Res. 19:446-483.

Ristaino, J. B., J.M. Duniway, and J.J. Marois. 1989. Phytophthora root rot and irrigation schedule influence growth and phenology of processing tomatoes. J. Amer. Soc. Hort. Sci. 114:556-561.

Rush, D.W. and E. Epstein. 1976. Genotypic responses to salinity: differences between salt-sensitive and salt-tolerant genotypes of the tomato. Plant Physiol. 57:162-166. . .

Sacher, R. F., R.C. Staples, and R.W. Robinson. 1983. Ion regulation and response of tomato to sodium chloride: A homeostatic system. J. Amer. Soc. Hort. Sci. 108:566-569.

Satour, M.M. and E.E. Butler. 1967. A root and crown rot of tomato caused by Phytophthora capsici and P. parasitic. Phytopathology 57:510-515.

Swiecki, T.J. 1984. Interactions between salinity and Phytophthora root rots of chrysanthemum and tomato. PhD Diss., Univ. of California, Davis. 109 p.

Swiecki, T.J. and J.D. MacDonald. 1988. Histology of chrysanthemum roots exposed to salinity and Phytophthora cryptogea. Can. J. Bet. 66:280-288. 